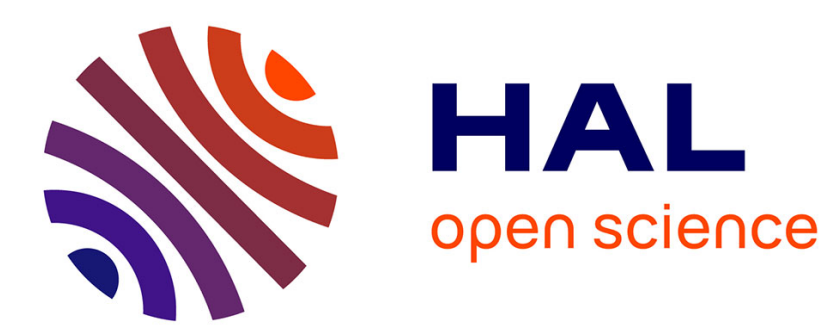

\title{
Fibrous ceramic-ceramic composite materials processing and properties
}

Roger Naslain

\section{To cite this version:}

Roger Naslain. Fibrous ceramic-ceramic composite materials processing and properties. Journal de Physique Colloques, 1986, 47 (C1), pp.C1-703-C1-715. 10.1051/jphyscol:19861107 . jpa-00225502

\section{HAL Id: jpa-00225502 https://hal.science/jpa-00225502}

Submitted on 1 Jan 1986

HAL is a multi-disciplinary open access archive for the deposit and dissemination of scientific research documents, whether they are published or not. The documents may come from teaching and research institutions in France or abroad, or from public or private research centers.
L'archive ouverte pluridisciplinaire HAL, est destinée au dépôt et à la diffusion de documents scientifiques de niveau recherche, publiés ou non, émanant des établissements d'enseignement et de recherche français ou étrangers, des laboratoires publics ou privés. 


\title{
R. NASLAIN
}

\author{
Laboratoire de Chimie du Solide du C.N.R.S. Université de \\ Bordeaux $I$ et Institut des Matériaux Composites, F-33405 Talence, \\ France
}

Résumé - L'introduction de fibres continues dans une matrice céramique est susceptible d'améliorer sa tenacité, si la liaison fibre-matrice est suffisamment faible, par microfissuration de la matríce et déchaussement des fibres. Les composites céramique-céramique sont élaborés par voie liquide ou gazeuse. Les plus importants sont constitués de matrices de verres, de carbures, de nitrures ou d'oxydes renforcées par des fibres de carbone, $\mathrm{SiC}$ ou $\mathrm{Al}_{2} \mathrm{O}_{3}$.

Abstract - The introduction of continuous fibers in a ceramic matrix can improve its toughness, if the fiber-matrix bonding is weak enough, due to matrix microcracking and fiber pull-out. Ceramic-ceramic composite materials are processed according to liquid or gas phase techniques. The most important are made of glass, carbide, nitride or oxide matrices reinforced with carbon, SiC or $\mathrm{Al}_{2} \mathrm{O}_{3}$ fibers.

\section{I - INTRODUCTION}

Ceramic-cermaic composite materials, i.e. materials made of brittle ceramic fibers (e.g.carbon, silicon carbide or alumina) embedded within a brittle ceramic matrix (e. g. carbon, carbides, nitrides, oxides, glasses or glass-ceramics) are, if one excepts the case of carbon-carbon, new materials which are still in a development stage. As a result, many important points concerning their processing and mechanical behavior are still imperfectly understood. This is particularly true for : (1) the role played by fiber-matrix (FM) interfaces, (2) the fracture mechanics of the materials or (3) the durability of the composites under conditions of severe environment (e.g. thermal cycling, cyclic stress loading, creep at high temperatures, effect of oxidizing atmospheres, etc...). Moreover, the high temperature characteristics of the fibers themselves have to be improved and the CCCM processing techniques presently available optimized.

The aim of the present contribution is to analyze the potential of CCCM as structure materials for high temperature applications, to present briefly the state of the art in the field of processing and to emphasize, on the basis of the limited number of references on the subject, some important fundamental problems arising from the development of the most promising materials (i.e. those with a glass-ceramic or silicon carbide matrix).

\section{II - WHY FIBER REINFORCED CERAMICS ?}

As engineering materials, ceramics have some important drawbacks related to their brittleness. When loaded in tension, they exhibit a linear elastic behavior up to failure which occurs at a low strain in a catastrophic manner (i.e. a crack, when initiated at a defect of the material, propagates very rapidly with a very low absorption of energy). The strength of a ceramic material is governed by its population of flaws. Since these flaws are statistically distributed within the material, the strength of ceramics depends on the volume which is considered (as a matter of fact, this is why ceramic fibers which are usually 5 to $20 \mathrm{\mu m}$ in diameter and even less for 
whiskers, are much stronger than the corresponding bulk ceramics). Thus, from a material designer point of view, the main drawbacks of monolithic ceramics appear to be : (1) the absence of any "plastic" deformation before failure and the low failure strain (with respect to metals) rendering almost impossible the accomodation of accidental over-loading, (2) the probabilistic character of failure strength end (3) the catastrophic failure and the related inability of maintaining stress at high strain values.

Several ways for improving the toughness of ceramics have been already explored with some success, e.g. by phase transformation or by utilizing particulate and short fiber reinforcements. It was logical to extend this effort to continuous refractory fibers even if, in this field, the situation could appear less favorable than for organic or metallic matrices. As a matter of fact, in most common composite materials, the fibers are imbedded in a low modulus matrix which has a much higher failure strain than them. Under loading, the fibers fail first when the material strain is equal to their failure strain. Since, the matrix is to weak to carry the additional load, it usually fails simultaneously, at least if the fiber volume fraction is high enough. In such a case, a reinforcing effect is observed due to the fact that $E_{f} \gg E_{m}$ (neglecting the contribution of matrix, $\left.\sigma_{C}^{R} / \sigma_{m}^{R}=\left(E_{f} / E_{m}\right) \cdot V_{f}\right)$.

For a ceramic, the situation is different inasmuch as $\varepsilon_{m}^{R}<\varepsilon_{f}^{R}$. Therefore, under loading, matrix fails first (and at low strain, as said above) (fig. 1). It is clear that no significant strengthening and toughning effects will arise if the fibers fail simultaneously. At such low strains, the fiber is still far from its failure strain but fibers are known to be, very notch-sensitive. The cracks occuring in the matrix at $\varepsilon_{C}=\varepsilon_{m}^{R}$ can act as stress $r$ isers at the fiber surface, especially if the fiber is tightly bonded to the matrix by a layer of chemical products resulting from diffusion phenomena (such products are usually very brittle) $/ 1-4 /$. In such a case of strong $F M$ bonding, which is unfortunately commonly observed in CCCM, cracking of matrix usually results in fiber (and composite) failure (i.e. after initiation, a crack may propagate relatively un-impeded through the composite, the brittle fibers being fractured in the primary crack plane with no significant contribution to the total work of fracture). A somewhat most favorable situation is found when the matrix is pre-stressed in compression (and simultaneously the fibers in tension) at room temperature after processing ( $i . e$. when $\alpha_{f l}>\alpha_{m}$ ). Under such conditions, a higher composite strain is necessary, under tension luading, to reach the matrix failure strain. Thus, the fi-
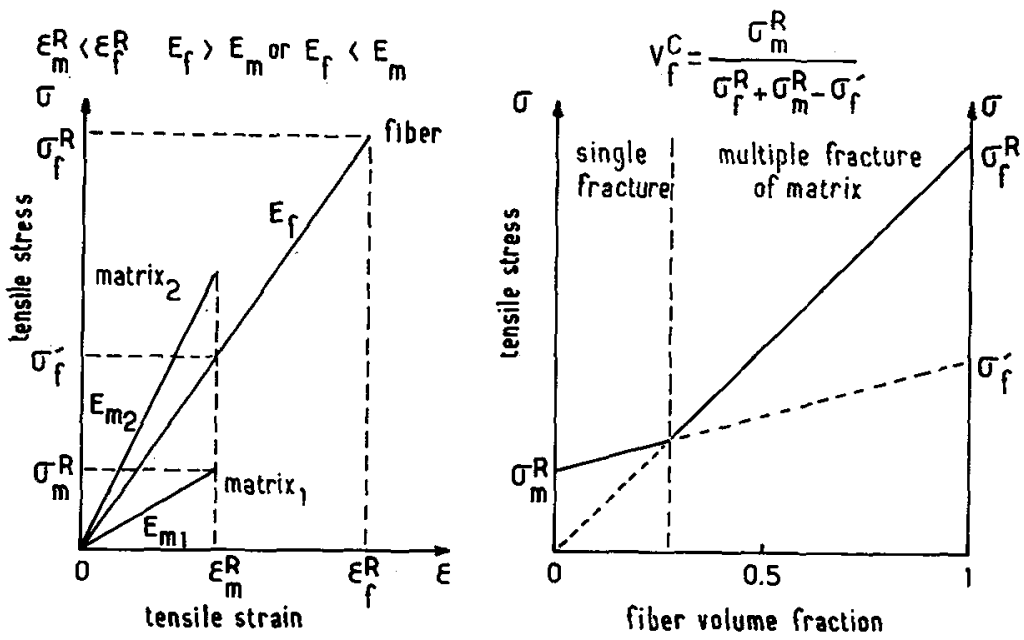

10. brittle fiber/brittle matrix composite

Fig. 1 : Schematic stress-strain curve and variation of failure stress vs fiber volume fraction for a 10-brittle fiber/brittle matrix composite 
bers could be loaded up to their failure stress and some reinforcing effect would be observed. However, this effect will be lost at temperatures approaching the fabrication temperature and failure remains brittle $/ 5 /$.

The mechanical behavior of CCCM can be dramatically improved when the fibers are only weakly bonded to the matrix inasmuch as FM interfaces may act as crack arresters (by weak bond one understands either an adhesion by mechanical friction or a weak chemical bond (e.g. of Van der Waals type)). When under loading $\varepsilon_{C}=\varepsilon_{m}^{R}$ matrix fails first as stated above. However, matrix failure may not induce that of the fibers if they are strong enough to sustain the additional load $\sigma_{m}^{R} \cdot V_{m}$, i.e. if ( fig. 1 ):

$$
\sigma_{m}^{R} \cdot v_{m}+\sigma_{f}^{\prime} \cdot v_{f}<\sigma_{f}^{R} \cdot v_{f} \quad \text { or } \quad v_{f}>v_{f}^{C}
$$

for a 1D-composite loaded axially, the weak FM interfaces blunting the microcracks and even deflecting part of them parallelly to the fibers. Microcracking will continue, at constant stress ( $\sigma_{m}^{R}$. E $E_{C}$ ) if matrix has a well defined $\varepsilon_{m}^{R}$ value, untill the whole matrix is broken down into a set of fragments of length 1 between $x^{\prime}$ and $2 x^{\prime}$ where $x^{\prime}$ is determined by the interfacial shear stress $\tau_{i}$ (fig. 2 ). If the load is still increased, the fibers can be now further stretched (due to some slipping through matrix fragments and local debonding) up to their failure strain. Since, under such conditions, matrix remains unloaded, the Young modulus of the composite is $E_{f}, V_{f} / 6 /$.

Matrix microcracking exhibits some very important features : (1) it occurs through the body of the composite (whereas, in single fracture, deformation is limited to the vicinity of the crack plane), (2) it corresponds to a significant increase in failure strain (with respect to unreinforced matrix) and to an energy absorption under rising loading conditions. It thus appears that matrix microcracking in CCCM plays, at least on a formal point of view, a role equivalent to that played by work-hardening in metals before failure.

As illustrated schematically in fig. 3, weak FM interfaces are responsible for several energy absorbing mechanisms as cracks propagate through the material, namely FM debonding, FM post-debonding friction and fiber pull-out (the latter being usually the most important) /7/. When such phenomena occurs, failure of the brittle fiber/ brittle matrix is no longer catastrophic, the stress decreasing only slowly (usually in a discontinuous manner) as the strain is further increased after UTS has been reached (fig. 4) $/ 8 /$.
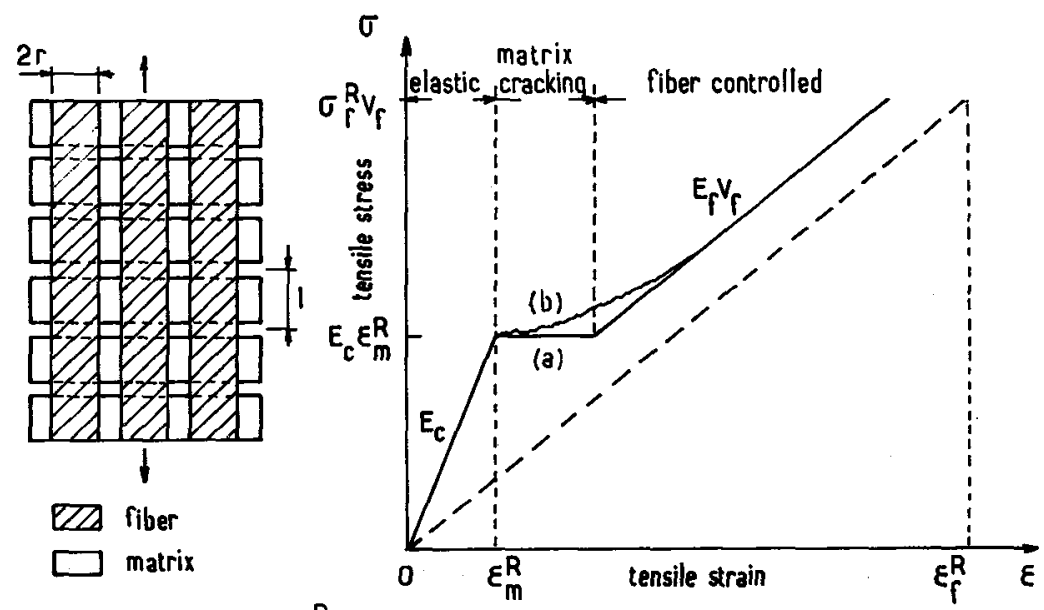

$$
x^{\prime}<1<2 x^{\prime} \quad x^{\prime}=\frac{V_{m}}{V_{f}} \cdot \frac{\sigma_{m}^{R} r}{2 \tau}
$$

Fig. 2 : Idealized tensile stress-strain curve for a 1D-brittle fiber/brittle matrix composite (with $\varepsilon_{m}^{R}<\varepsilon_{f}^{R}$ ) showing multiple fracture of the matrix/6/ 


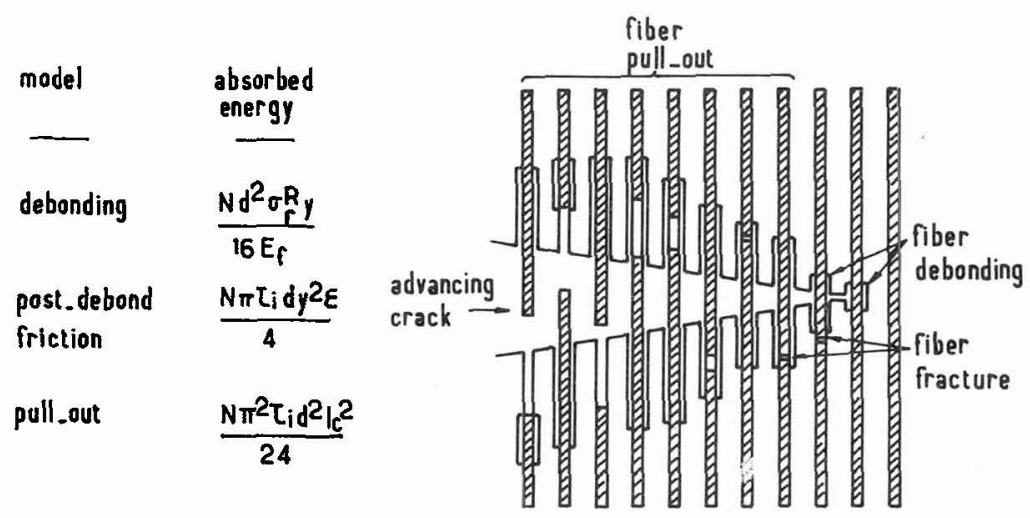

\footnotetext{
$y$ debonded length

lc critical length

$\varepsilon$ diffence in strain (FM)

$N$ number of fibers
}

from D.C.Phillips, 1985

Fig. 3 : Energy absorbing mechanisms in a brittle fiber/brittle matrix composite with weak fiber-matrix interfaces /7/

It appears from the above analysis that controlling the nature of the FM interfaces is a key parameter in the processing of CCCM : a minimum of FM adhesion is necessary for a proper load transfer between fibers and matrix but a too strong bonding is detrimental to both strength and toughness. FM bonding can be the result of mechanical (i.e. friction) or/and chemical (e.g. diffusion) considerations. Since CCCM are usually processed at rather high temperatures, too large differences between the coefficients of thermal expansion (CTE) of fibers $\alpha_{f}$ and matrix $\alpha_{m}$ will raise a state of internal stress during cooling. When $\alpha_{m}>\alpha_{f_{r}}$ the FM interfaces will be in a state of compression thus limiting the possibility of fiber pull-out. On the contrary, when $\alpha_{m}<\alpha_{f \Gamma}$ the FM interfaces will be in tension $/ 5 /$. In such a case, debonding is much easily achieved. Most CCCM are reactive systems at high temperatures and the diffusion phenomena that take place at the FM interfaces usually result in strong bonding and, thus, in low failure strains and brittle failures, as discussed above. However,

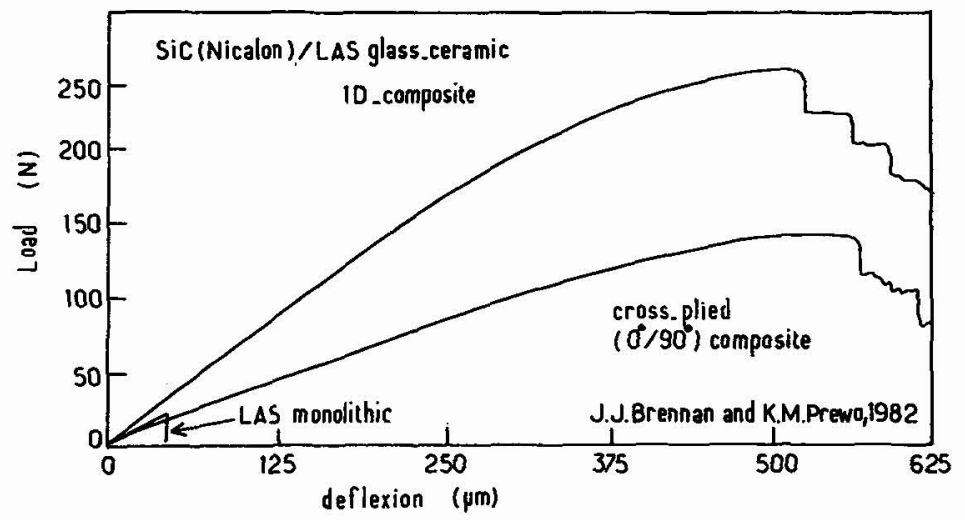

Fig. 4 : Mechanical behavior in flexion, at room temperature, of SiC(Nicalon)/glass ceramic composite material (notched beam) /8/ 
the bond strength depends on many parameters which are more or less well-controlled (e.g. the reactivity of the fiber which depends on its microstructure, the existence of an inorganic sizing or of products resulting from the pyrolysis of an organic sizing, the fabrication temperature, the matrix composition, etc...). An efficient way to get weak FM interfaces in a CCCM is to form a thin layer of low shear strength material around each fiber (e.g. pyrocarbon). Such a layer can be either deposited at the fiber surface prior to the composite fabrication or formed in-situ by a FM chemical reaction occuring during the composite fabrication. A good example of this latter case has been given recently by J.J. Brennan for SiC(Nicalon)/glass-ceramic composites. AES microanalysis has shown that a thin layer of carbon-rich material was present at the FM interfaces in strong tough composites and absent in weak brittle composites (fig. 5) $/ 9 /$.

In order to optimize the processing conditions for a given CCCM, it is important to have a method for measuring the interface shear strength $\tau_{i}$. Several techniques can be used at least when the FM bond is not too strong. They are based on : (1) the measurement of the spacing of the matrix microcracks $/ 10 /$, (2) the measurement of the critical stress at which microcracking occurs (fig. 6) /11,12/ or (3). an indentation technique with a microhardness diamond tip $/ 10 /$. As an example, table I gives the corresponding data for a SiC(Nicalon)/glass-ceramic tough composite. As expected, the $\tau_{i}$ values are low.

\begin{tabular}{|c|c|c|c|}
\hline Techniques & inter-crack spacing & critical stress $\sigma\left(^{*}\right)$ & indentation \\
\hline$\tau_{i}(\mathrm{MPa})$ & 1.7 & 2.5 & 2.5 \\
\hline
\end{tabular}

Table I : Estimation of the interface shear stress $\tau_{i}$ for SiC(Nicalon)/glassceramic composite $/ 10,11,12 /$.

\section{III - PROCESSING TECHNIQUES FOR CCCM}

Ceramics reinforced with continuous refractory fibers can be processed according to liquid or gas phase routes (solid state techniques are generally not used regarding the brittleness of the fibers and the absence of plasticity of ceramic matrices).

The impregnation of a fibrous material with liquid ceramic matrices is necessarily a technique of limited interest due to the high melting point and chemical reactivity

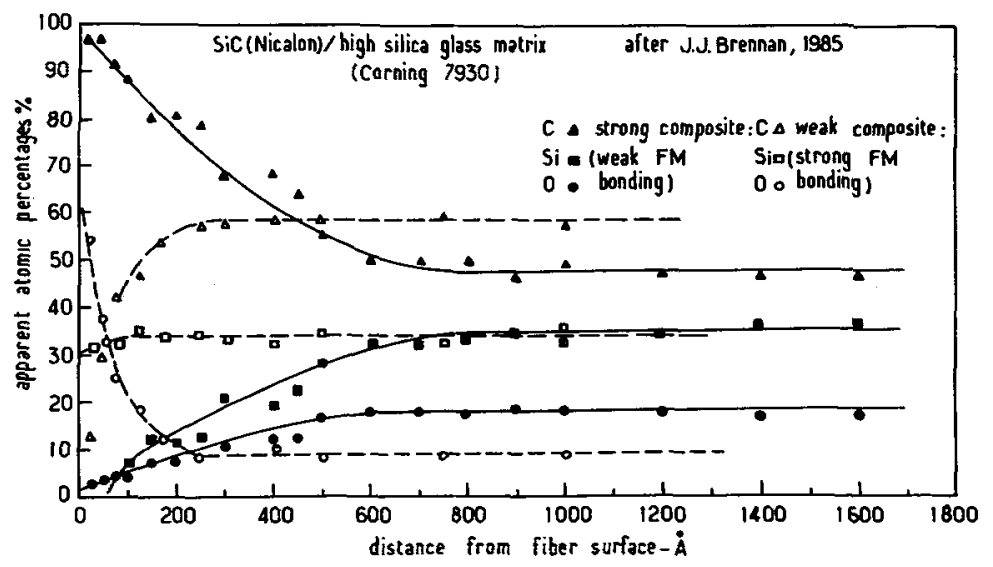

Fig. 5 : Scanning AES analysis of SiC(Nicalon) fiber from a strong (or a weak) 10-SiC /glass-ceramic composite fracture surface showing the ogcyrence (or not) of a carbon-rich interphase at the fiber-matrix interface $/ 9$ \% 


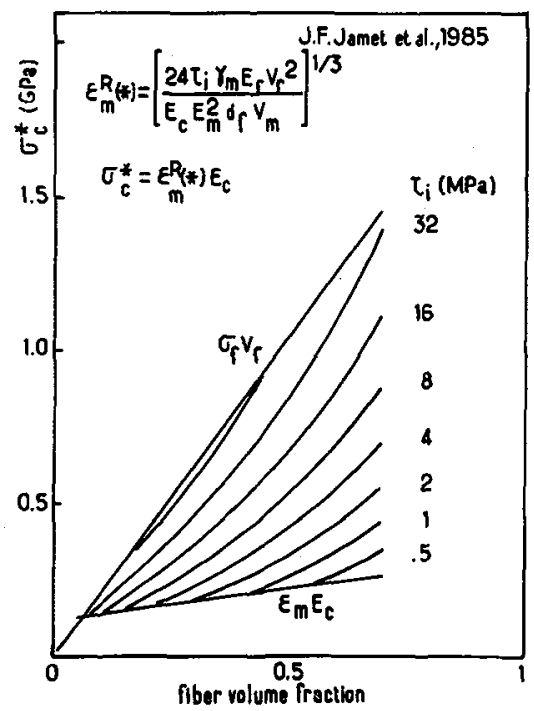

Fig. 6 : Critical stress diagram for a 1D-SiC(Nicalon $/$ /glass-ceramic composite material $/ 11 /$

of most ceramics (e.g. carbides, nitrides or oxides). On the other hand, it is a suitable technique for glass (or glass-ceramic) matrices since above $\mathrm{Tg}$ (i.e. between $600-1000^{\circ} \mathrm{C}$ for silica-based glasses) they are in a viscous state. In such a case, the sequence of operations is : (1) impregnation of the fibrous material (as tows or fabrics) with a slurry, (2) drying which results in a "prepreg", (3) stacking of prepreg sheets, (4) consolidation at high temperature under pressure and eventually (5) ceramization treatment $/ 8,13,14 /$.

Ceramic matrices can also be formed in-situ by pyrolysis of organo-metallic precursors. Such a technique has been used for a long time for the fabrication of carboncarbon from organic resins or pitches. It has been very recently extended to other refractory materials such as silicon carbide, silicon nitride or oxides, the organometallic precursors being respectively polycarbosilanes (or polysilanes), polysilazanes and metalalkoxides $/ 15-17 /$. This technique still raises a number of fundamental problems among which the most important are related to the choice of the precursor and pyrolysis conditions in order to achieve high pyrolysis yields with limited shrinkage (many precursors give rise to an important evolution of gaseous species and to ceramic matrices containing many cracks). As a result, several impregnation/firing sequences have to be performed or inert fillers must be added to the organo-metallic precursor. In this latter direction, J. Jamet et al. have recently suggested to add colloidal hex-BN to vinyl polysilane and to use the thus-prepared high viscosity slurry for the in-situ synthesis of hybrid SiC-BN matrices /18/. In the case of oxide or glass matrices a sol-gel technique can be utilized with three important steps : (1) impregnation of the fibrous material with a sol (based on alkoxysilanes, metalalkoxides or/and metal salts), (2) in-situ gelation (hydrolytic polycondensation) leading to a "prepreg" and (3) elimination of water by heating and sintering $/ 16,19 /$.

A variety of high quality CCCM have been obtained according to the so-called CVI route (chemical vapor infiltration) derived from the previously known CVD technique (chemical vapor deposition). Many common ceramics can be formed, on a heated substrate, from gaseous precursors (e.g. carbon from $\mathrm{CH}_{4}$ or $\mathrm{C}_{3} \mathrm{H}_{8}$, silicon carbide from $\mathrm{CH}_{3} \mathrm{SiCl}_{3}-$ $\mathrm{H}_{2}$, boron carbide from $\mathrm{BCl} \mathrm{C}_{3}-\mathrm{CH}_{4}-\mathrm{H}_{2}$, titanium carbide from $\mathrm{TiCl}_{4}-\mathrm{CH}_{4}-\mathrm{H}_{2}$, silicon or boron nitrides from $\mathrm{SiCl}_{4}-\mathrm{NH}_{3}$ or $\mathrm{BF} 3-\mathrm{NH}_{3}$, alumina from $\mathrm{AlCl} 3-\mathrm{CO}_{2}-\mathrm{H}_{2}$, etc...). As illustrated in fig. 7 , the CVI of a porous substrate, here a preform made of fibers, involves several important steps : the diffusion of the gaseous source species through 


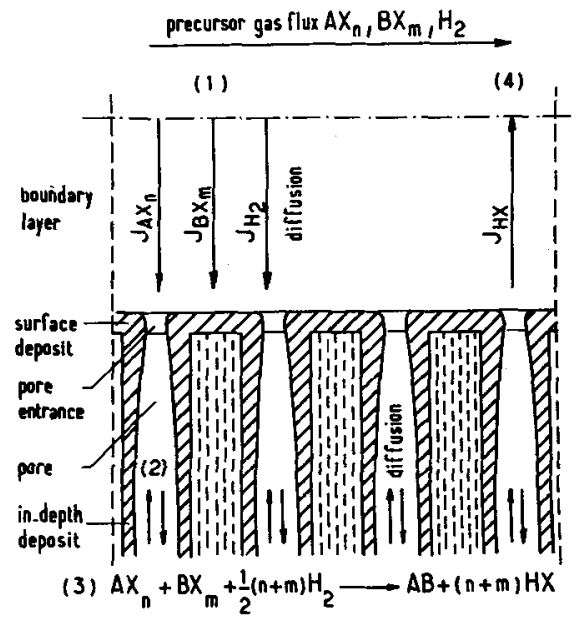

Fig. 7 : Mechanisms involved in the processing of a ceramic/ceramic composite material by CVI /20/

a stagnant boundary layer (1) and within the pores (2), a surface reaction between adsorbed species (3) and the diffusion of the gaseous reaction products in the pores (4) and through the boundary layer (5) $/ 20 /$. It is generally accepted that the rate of deposition of the solid is controlled by surface reaction kinetics at low temperatures and pressures, and by diffusion of the gas species at high temperatures and pressures. In order to favor deposition in the pore network of the substrate (with respect to that occuring on the external surface) : (1) the process should be controlled by surface reaction kinetics, (2) supersaturation of the gas phase in source species, near pore entrances, must be high enough and (3) deposition rate has to be sufficiently low. Such conditions imply deposition temperature, total pressure and gas flow rate as low as possible $/ 20,21,22,23 /$. When they are properly fulfilled, densification of the porous fiber preform proceeds smoothly to almost completion ( $f i g .8)$. Dn the contrary, when one of the main parameters (i.e. especially temperature or pressure) has a too high value, even for a short time, the pore entrances are sealed by the deposit and densification stops (in such a case, a surface machining is necessary to re-open the pores) $/ 20$. The CVI-process has several important advantages :

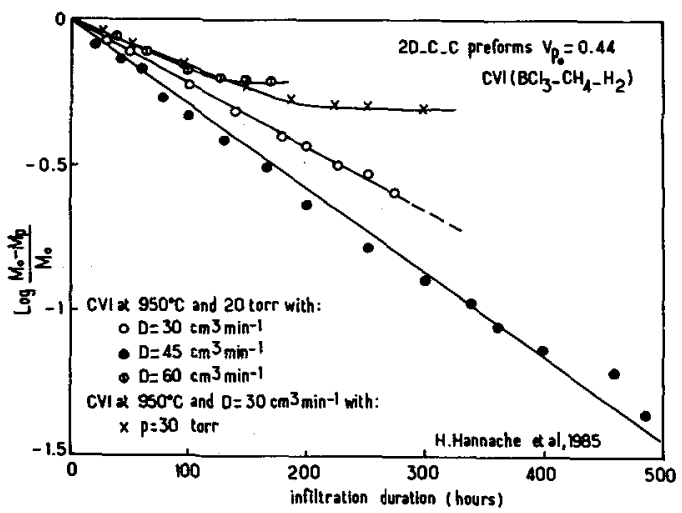

Fig. 8 : Kinetics of densification of a porous $2 D-C-C$ preform by $B_{4} C$ according to CVI /20/: Mo highest achievable ceramic mass, Mp ceramic infiltrated mass 
(1) it can be applied to preforms of complex shape and low porosity, (2) it is performed at rather low temperatures (usually $800-1000^{\circ} \mathrm{C}$ ) thus limiting fiber degradation, (3) in-situ fiber surface treatment with a view to control FM bonding can be easily made prior to densification and (4) a large number of parts can be simultaneously densified when isothermal deposition chambers are used. On the other hand, it is a slow process limited to those ceramics for which gaseous precursors are known. Improvement can be achieved with pression/temperature gradient furnaces $/ 20,24 /$.

\section{IV - SOME IMPORTANT CCCM FAMILIES}

\section{1 - Reinforced glasses or glass-ceramics}

Silica-based glasses (or glass-ceramics) provide several advantages, as matrix materials, over crystalline ceramics : (1) they exhibit a thermoplastic behavior above their $\mathrm{Tg}$ (which usually ly between $600-1000^{\circ} \mathrm{C}$ ) and thus glass matrix composites can be readily processed according to well known techniques, (2) they have a low Young modulus (i.e. $\sim 75 \mathrm{GPa}$ ) with respect to those of high performance fibers, (3) their physical properties (e.g. their CTE) can be adjusted by modifying the chemical composition and (4) they have an excellent behavior vis a vis a number of chemical environments $/ 8,11-14 /$.

As already discussed, glasses ( or glass-ceramics) reinforced with continuous carbon or silicon carbide fibers exhibit the typical features of tough ceramic-ceramic composites related to weak FM interfaces : i.e. matrix microcracking and energy absorbing mechanisms such as fiber pull-out. The use of high $V_{f}$ values (i.e. 50 to $60 \%$ ) and UHM carbon fibers (e.g. P100 from Union Carbide) results in 1D-composites of extremely high Young modulus (i.e. 300-350GPa) and dimension stability (low CTE) /14/. UTS value has high as $600-800 \mathrm{MPa}$ is commonly achieved in the $0^{\circ}$ direction and remains almost constant as temperature in increased up to $\mathrm{Tg}$ (where a peak is observed due to the increase in viscosity) (fig. 9). Glass and glass-ceramic matrix composites are tough materials with tensile failure strain of the order of $0,5 \%$ (vs $0.1-0.2 \%$ for an unreinforced. LAS glass-ceramics) and extremely high $K_{I C}$ values exhibiting thermal variations comparable to those of strength (fig. 10) /8/. Finally the oxidation resistance is excellent for $\mathrm{SiC}$ or $\mathrm{Al}_{2} \mathrm{O}_{3}$ fiber-based composites and much limited when carbon fibers are used.

Such composites could be used as structure materials for applications at medium temperatures.

\section{2 - Carbon-carbon/ceramic composite materials}

C-C/ceramic composite materials have been developed to overcome the main draw-

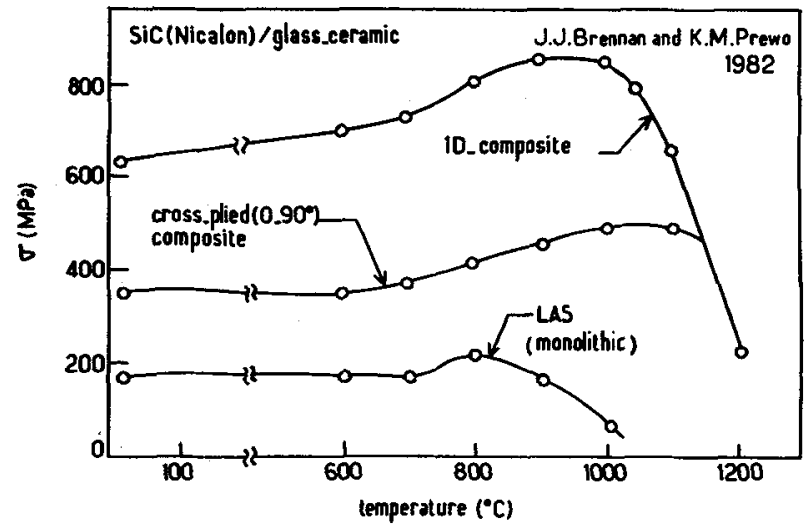

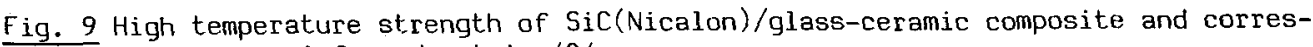
ponding unreinforced matrix /8/ 


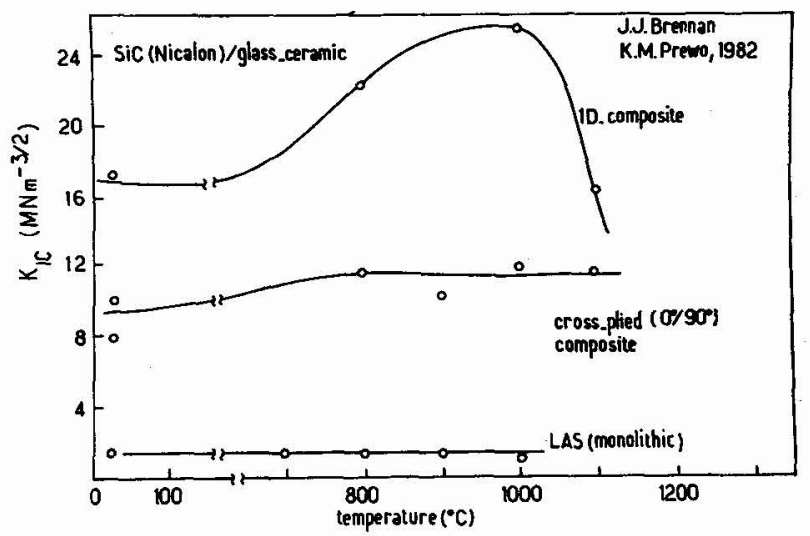

Fig. 10 : High temperature toughness of $\mathrm{SiC}($ Nicalon)/glass-ceramic composite and corresponding unreinforced matrix /8/

back of carbon-carbon, i.e. their very poor oxidation resistance. In such materials, part of the carbon matrix is replaced by another refractory material known for its excellent mechanical properties or/and oxidation resistance e.g. silicon, boron or titanium carbides as well as boron nitride. A lot of work has been done on 2D-composites in which the carbon fiber reinforcement is made of fabrics. The materials are processed according to a two step CVI procedure : (1) consolidation of a 2D-C preform with a small amount of pyrocarbon and (2) densification with the ceramic matrix /20 $22 /$.

As shown in fig. 11, the stress-strain curves of 2D-C-C/ceramic exhibit linear elastic and "pseudo-plastic" domains, the latter being related to damaging mechanisms (e.

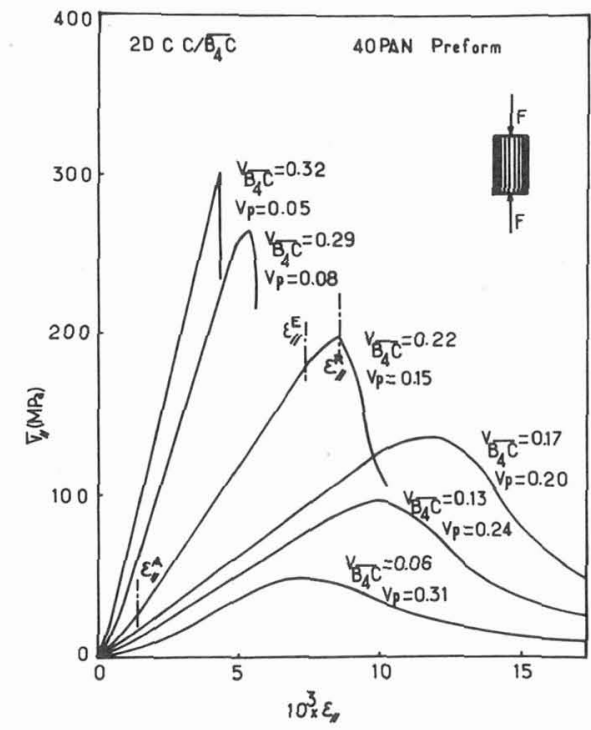

(a)

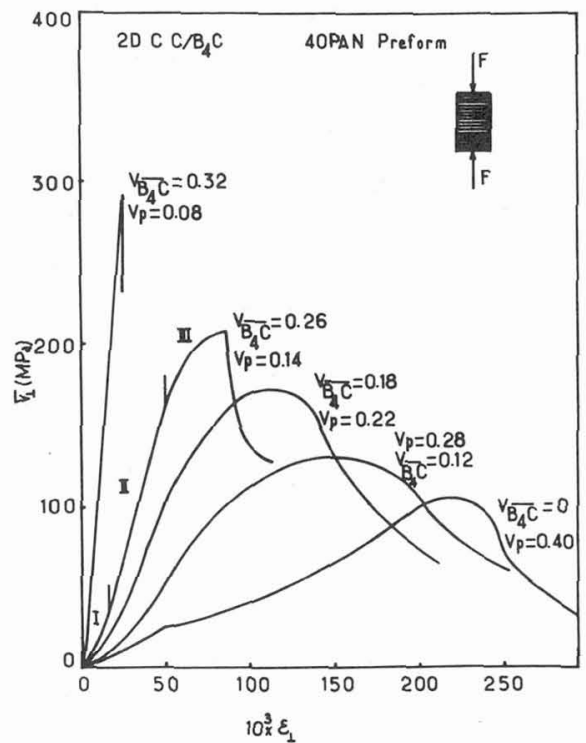

(b)

Fig. 11 : Mechanical behavior, in compression, of $2 \mathrm{D}-\mathrm{C}-\mathrm{C} / \mathrm{B}_{4} \mathrm{C}$ composite materials for increasing $\mathrm{B}_{4} \mathrm{C}$ volume fractions : (a) in para-direction and (b) in orthodirection $/ 20 /$ 


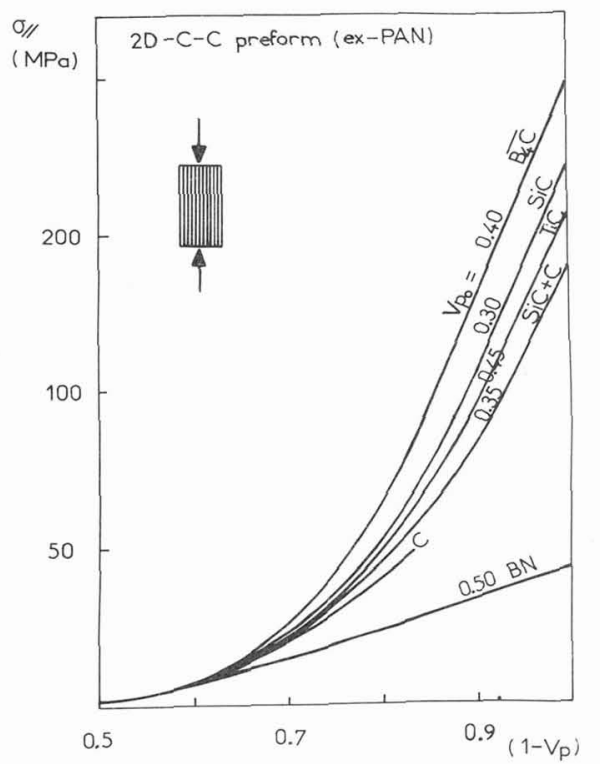

(a)

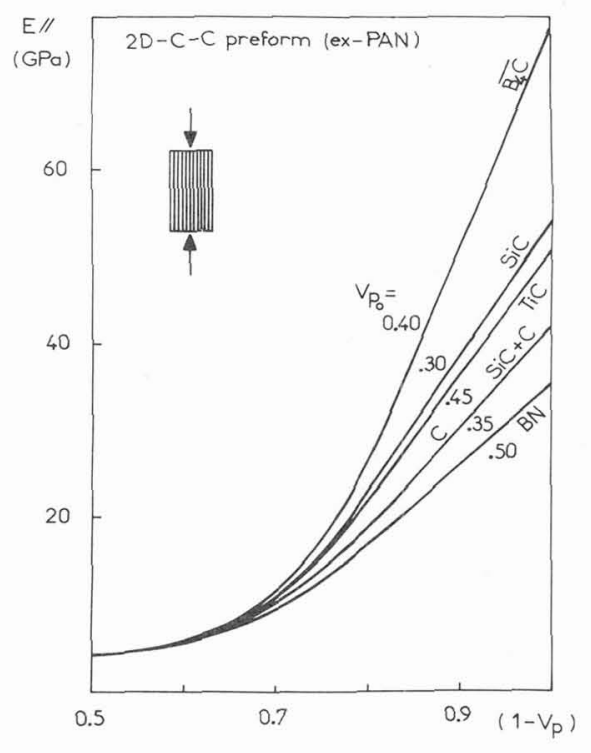

(b)

Fig. 12 : Variations of the compression stength and Young modulus of 2D-C-C/ceramic composite materials as a function of compacity $\left(1-V_{p}\right)$ (load applied in $p-$ direction) $/ 20 /$

g. matrix microcracking). Both the Young modulus and failure strangth increase with raising ceramic volume fraction, the effect of $V_{I}$ being more significant, as could be expected, for the strong and stiff $\mathrm{B}_{4} \mathrm{C}$ matrix than for the weak $\mathrm{BN}$ matrix (fig. 12). The oxidation resistance is good for $\mathrm{C}-\mathrm{C} / \mathrm{BN}$ or $\mathrm{C}-\mathrm{C} / \mathrm{B}_{4} \mathrm{C}$ and excellent for $\mathrm{C}-\mathrm{C}-\mathrm{SiC}$ provided a coating is applied on the external surface of the samples $/ 22,25 /$.

\section{3 - Silicon carbide/silicon carbide composite materials}

SiC (Nicalon type)/ $\mathrm{SiC}$ (CVI) composites are undaubtedly the most promising CCCM for applications at high temperatures. They are another example of tough system, at least when they are well processed, built from brittle components, as shown in fig. 13 and $14 / 23,24,26 /$. Since in this case $E_{f} \leqslant E_{m}$ (i.e. $E_{f}$ (Nicalon) $\sim 200 \mathrm{GPa}, E_{f}$ (AVCO filament) $\sim 400 \mathrm{GPa}$ vs $\mathrm{E}_{\mathrm{m}}(\mathrm{SiC}-\mathrm{CVI}) \sim 400 \mathrm{GPa}$ ), no strengthning effect is ex-

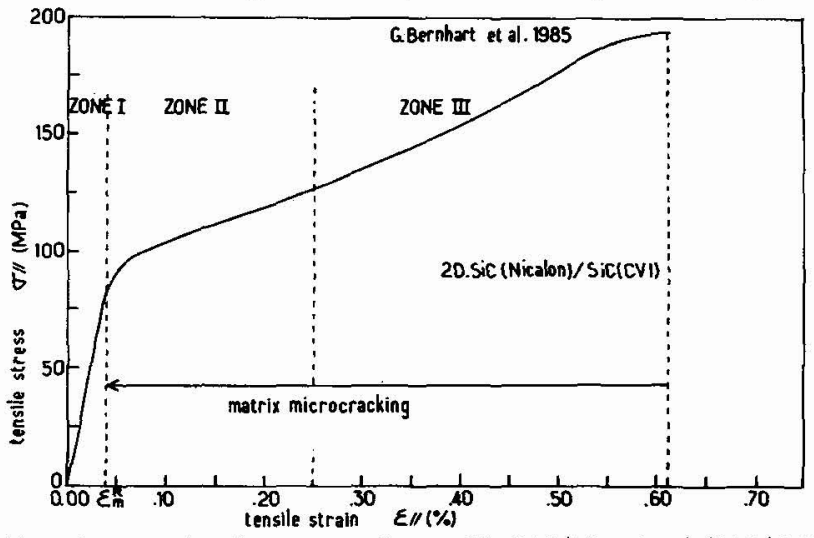

Fig. 13 : Tensile stress-strain curve for a 2D-SiC(Nicalon)/SiC(CVI) composite /27/ 


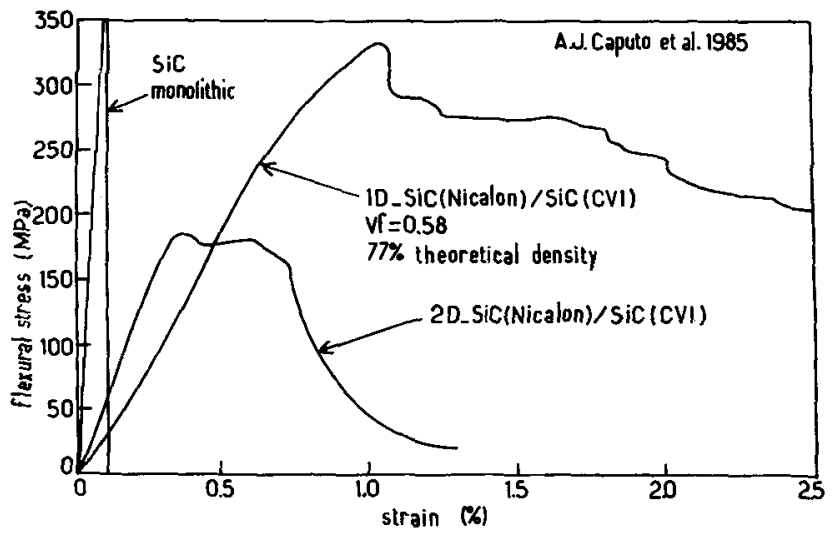

Fig. 14 : Stress-strain curves for SiC-SiC composite materials and monolithic silicon carbide /24/

pected. As illustrated in fig. 15, the strength of $\mathrm{SiC} / \mathrm{SiC}$ composites is comparable to that of the best sintered $\mathrm{SiC}$ ceramies $/ 23,26 /$. It is noteworthy that $50 \%$ of the RT strength of a $2 \mathrm{D}-\mathrm{SiC}-\mathrm{SiC}$ is maintained at $\sim 1500^{\circ} \mathrm{C}$.

The main interest of SiC-SiC composites vs monolithic silicon carbide lies in their exceptional toughness, as shown in $\mathrm{fig} .16 / 27 /$. Values of $\mathrm{K}_{\mathrm{TaC}}$ as high as $\sim 30 \mathrm{MPa}$ $\mathrm{m}^{\frac{1}{2}}$ have been reported for both $2 \mathrm{D}-\mathrm{SiC} / \mathrm{SiC}$ and $2 \mathrm{D}-\mathrm{C}-\mathrm{C} / \mathrm{SiC}$ composites from RT to $1000-$ $1200^{\circ} \mathrm{C}$. Even if the use of $\mathrm{K}_{\mathrm{C}}$ parameters can be questioned here it seems that such composites could have the highest toughness reported for a ceramic material.

Finally, the oxidation resistance of $\mathrm{SiC}-\mathrm{SiC}$ composites is excellent as could be predicted from the intrinsic properties of silicon carbide.

SiC-SiC and C-SiC composites are the first CCCM presently fabricated on an industrial basis. They could be used in high temperature engines as well as in chemical engineering.

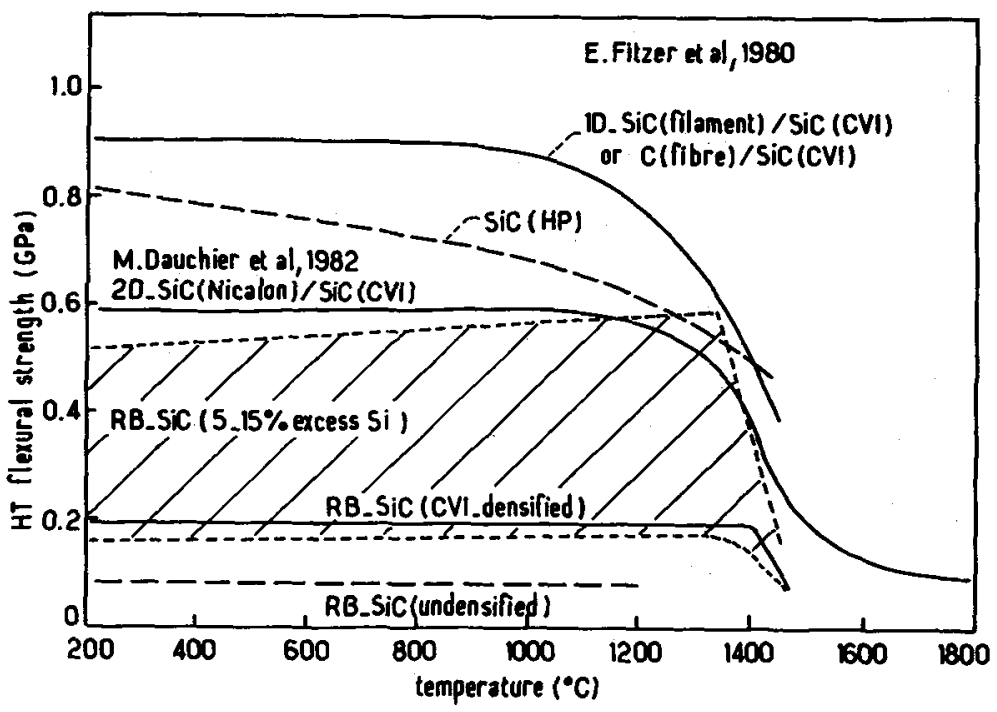

Fig. 15: High temperature strength of SiC-based ceramics /23,26/ 


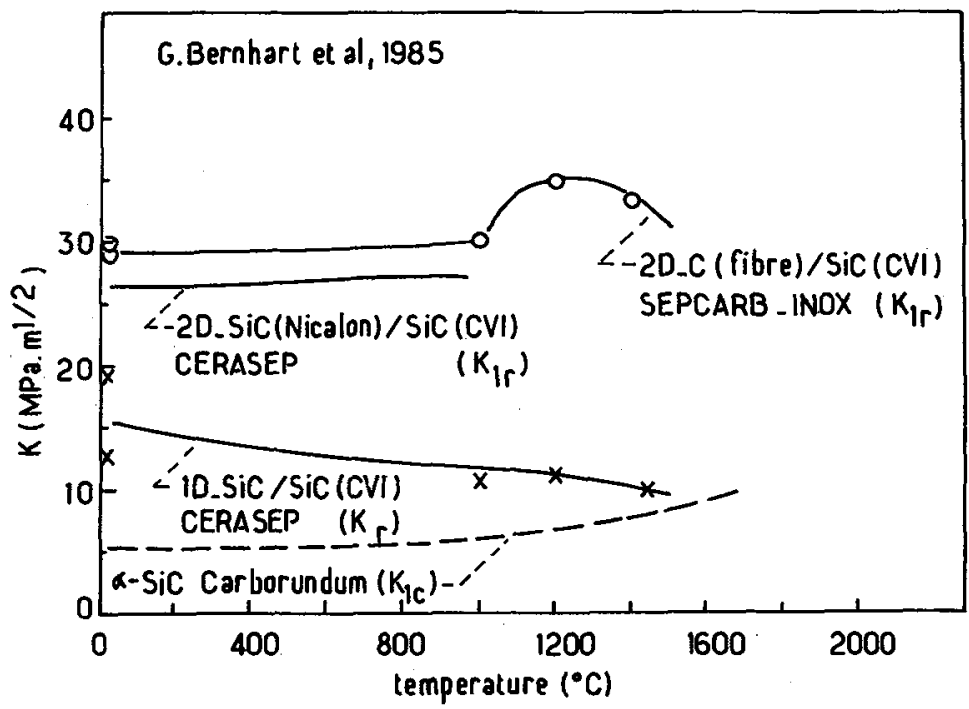

Fig. 16 : High temperature toughness of SiC-based ceramics /27/

\section{ACKNOWLEDGEMENTS}

The author wishes to thank P. Martineau and N. Pinna from Institute for Composite Materials for their contribution. to the preparation of the manuscript.

\section{REFERENCES}

1/ Metcalfe, A.G., J. Composite Mater., 1 (1967) 356

/2/ Ochiai, S. and Murakami, Y., J. Mater. Sc., 14 (1979) 831

13/ Dchiai, 5., Urakawa, S., Ameyama, K. and Murakami, Y., Meta?. Trans. A, 11A (1980) 525

14/ Martineau, P., Pailler, R., Lahaye, M. and Naslain, R., J. Mater. Sc., 19 (1984) 2749

15/ Donald I.W. and Mc Millan P.W., J. Mater. Sc., 11 (1976) 949

16/ Aveston, J., Cooper, G.A. and Kelly, A., Proc. The Properties of Fibre Composites Nat. Phys. Lab., IPC Sc. and Technol. Press, London (1971) 15

/7/ Phillips, D.C., in Survey of the Technol. Requirements for High Temper. Mater. $R$ and $D$, Section 3 : Ceramic Composites for High Temper. Eng. Appl. (Davidge R.W. ed.), Comm. Europ. Communities, (1985) 48

/8/ Brennan, J.J. and Prewo, K.M., J. Mater. Sc., 17 (1982) 2371

19/ Brennan, 3.J., Proc. 21th. Univ. Conf. Sc. Ceramics "Tailoring Multiphase and Composite Ceramics", July 17-19, Penn. State Univ., 1985

/10/ Marshall, D.B. and Evans, A.G., private communication, 1985

111/ Jamet, J.F., Abbé, D. and Guyot, M.H., Proc. ICCM-V (Harrigan, W.C. et al. eds.), San Diego, July-Aug. 1985, TMS-AIME, Warrendale (Penn.), pp. 569-585

112/ Jamet, J.F., Lewis, D. and Luh, E.Y., Proc. 8th. Ann. Conf. Composites and Adv. Ceram. Mater., Jan 15-18, 1984, Cocoa Beach (Fl.), AC5, Columbus (Dh.), pp. 625641

113/ Prewo, K., J. Mater. Sc., 17 (1982) 3549

14/ Prewo, K.M., Proc. 21th. Ann. Conf. Sc. Ceramics "Tailoring Multiphase and Composite Ceramics", July 17-19, Penn. State Univ., 1985

/15/ Hasegawa, Y. and Okamura, K., J. Mater. Sc. Letters, 4 (1985) 356

/16/ Wills, R.R., Markle, R.A. and Mukherjee, S.P., Ceram. Bull., 62 (1983) 904

/17/ Walker, B.E., Rice, R.W., Becher, P.F., Bender, B.A. and Coblenz, W.S., Ceram. Bull., 62 (1983) 916

/18/ Jamet, J., Spann, J.R., Rice, R.W., Lewis, D. and Coblenz, W.S., Proc. 8th. Ann. 
Conf. on Composites and Adv. Ceram. Mater., Janv. 15-18, 1984, Cocoa Beach (F1.) ACS, Columbus (Oh.), pp. 677-694

119/ Fitzer, E. and Schlichting, J., High Temper. Sc., 13 (1980) 149

/20/ Naslain, R. and Langlais, F., Proc. 21th. Univ. Conf. Sc. Ceramics "Tailoring Multiphase and Composite Ceramics", July 17-19, Penn. State Univ., 1985

121/ Rossignol, J.Y., Langlais, F and Naslain, R., Proc. CVD-IX (Robinson, Mc D. et al., eds.), Cincinnati, 1984, The Electrochem. Soc., Pennington, pp. 596-614

122/ Naslain, R., Rossignol, J.Y., Hagenmuller, P., Christin, F., Heraud, L. and Choury, J.J., Rev. Chimie Minerale, 18 (1981) 544

123/ Fitzer, E., Hegen, D. and Strohmeier, H., Rev. Int. Hautes Temper. Réfract., 17 (1980) 23

124/ Caputo, A.J., Lackey, W.J. and Stinton, D.P., Proc. 9th. Ann. Conf. on Composites and Adv. Ceram. Mater., Jan. 20-23, 1985, Cocoa Beach, F1., ACS, Columbus (Oh.)

/25/ Naslain, R., Quenisset, J.M., Rossignol, J.Y., Hannache, H., Lamicq, P., Choury, J.J., Heraud, L. and Christin, F., Proc. ICCM-V (Harrigan, W.C. et al., eds.), San Diego, July-Aug., 1985, TMS AIME, Warrendale (Penn.), pp. 499-514

126/ Dauchier, M., Lamicq, P. and Mace, J., Rev. Int. Hautes Temper. Refract., 19 (1982) 285

/27/ Bernhart, G., Lamicq, P. and Mace, J., Ind. Ceramique, 790 (1985) 51 